\title{
Cabergoline in the Treatment of Peripartum Cardiomyopathy
}

\section{Cabergolina no tratamento da cardiomiopatia periparto}

\author{
James D. Fett ${ }^{1}$ \\ ${ }^{1}$ Department of Adult Medicine, Hospital Albert Schweitzer, \\ Deschapelles, Haiti
}

Rev Bras Ginecol Obstet 2016;38:423-424.

It is premature to make a recommendation for treatment of peripartum cardiomyopathy (PPCM) with prolactin inhibition (bromocriptine or cabergoline) as in the one-case report of Melo et al. ${ }^{1}$

There are now multiple reports of trials for PPCM subjects in the use prolactin inhibition treatment compared with non-use of this modality that show no statistically significant benefit in recovery outcomes at 6 and 12 months postpartum. ${ }^{2,3}$

Furthermore, there is still potential risk to the use of these agents in the peripartum setting, with multiple reports of cardiovascular catastrophes, including myocardial infarction, coronary artery spasm, and stroke. ${ }^{4}$

What is still needed is a carefully controlled investigation of use of bromocriptine or cabergoline vs non-use as adjunct or non-adjunct to conventional therapy for heart failure with systolic dysfunction.

Melo et al emphasize the need for effective treatment of PPCM “[...]particularly in developing countries." We have shown the devastating effect on otherwise healthy neonates whose mothers died from PPCM, with high mortality rates for these children as a consequence of losing the source of breast milk when a mother dies. ${ }^{5}$ An effective

\section{Author Reply}

We would like to thank the interest of Dr. James D. Fett in our article and to clarify some doubts.

The case report of Melo et $\mathrm{al}^{1}$ sought to describe an otherwise satisfactory progress with the use of dopaminergic agonists (bromocriptine and cabergoline). This treatment strategy is based on an experimental observation of prevention of peripartum cardiomyopathy (PPMC) in mice by block-

received

July 15, 2016

accepted

August 17, 2016

published online

August 31, 2016
Address for correspondence James D Fett, MD, Department of Adult Medicine, Hospital Albert Schweitzer, Deschapelles, Haiti, c/o 2331 Mt. Hood Ct. SE, Lacey, WA 98503, United States

(e-mail: Fett.sprunger@comcast.net).

program to provide alternative nutrition must accompany any treatment program that deprives newborns of a mother's breast milk. This is an issue of concern particularly in developing countries.

\section{References}

1 Melo MA, Carvalho JS, Feitosa FE, et al. Peripartum cardiomyopathy treatment with dopamine agonist and subsequent pregnancy with a satisfactory outcome. Rev Bras Ginecol Obstet 2016;38(6): 308-313

2 Fett JD. Peripartum cardiomyopathy: challenges in diagnosis and management. Expert Rev Cardiovasc Ther 2016;14(9):1035-1041 [Epub ahead of print]

3 McNamara DM, Elkayam U, Alharethi R, et al; IPAC Investigators. Clinical Outcomes for Peripartum Cardiomyopathy in North America: Results of the IPAC Study (Investigations of Pregnancy-Associated Cardiomyopathy). J Am Coll Cardiol 2015;66(8):905-914

4 Jeanneteau P, Bière L, Mercier MB, Descamps P, Sentilhes L. Bromocriptine-induced coronary spasm in postpartum. Eur J Obstet Gynecol Reprod Biol 2014;179:258-259

5 Fett JD, Murphy JG. Infant survival in Haiti after maternal death from peripartum cardiomyopathy. Int J Gynaecol Obstet 2006; 94(2):135-136 ing prolactin bromocriptine. A randomized small pilot study and several observational reports have suggested a beneficial response to bromocriptine therapy in patients with PPMC. ${ }^{2-4}$ Sliwa et $\mathrm{al}^{2}{ }^{2}$ in a prospective single-center, proof-of-concept pilot held in South Africa, evaluated the effect of prolactin lock with bromocriptine. Treatment with this medicament was administered after the diagnosis at a dosage of $2.5 \mathrm{mg}$ 
twice a day for 2 weeks followed by $2.5 \mathrm{mg}$ a day for 6 weeks, in addition to the standard heart failure therapy in 10 patients with PPMC. This treatment resulted in a significantly higher rate of left ventricular recovery at 6 months compared with a group of 10 women with PPMC treated alone with standard treatment for heart failure $( \pm 31 \%$ versus $\pm 9 \%, p=0.012$ ).

Furthermore, there was a lower mortality rate in the treated group ( 1 versus 4 patients) and an index of poor outcome defined as a combined end point of death, New York Heart Association (NYHA) functional class III/IV or left ventricular ejection fraction (LVEF) $<35 \%$ at 6 months. ${ }^{5}$ A multicenter German study with a randomized controlled prospective open design evaluated females with newly diagnosed PPMC according to the criteria of the European Society of Cardiology, with an LVEF $<35 \%$. Patients were randomized $1: 1$ to either best supportive care (BSC), including standard heart failure therapy, and 8 weeks of bromocriptine therapy ( $2.5 \mathrm{mg}$ b.i.d. 14 days and $2.5 \mathrm{mg}$ q.d. from the from 15 to 56) or BSC 1 more week low-dose bromocriptine (2.5 mg q.d.) to a prophylactic anticoagulant therapy dose administered during bromocriptine treatment period in both groups. To date, the observations of this study indicated a good safety and tolerability of bromocriptine in PPMC patients. So far, none of the patients had to prematurely terminate bromocriptine due to safety concerns. In particular, no thrombotic complications associated with bromocriptine were recorded. The results of this study may have significant impact on the future management of PPMC patients. ${ }^{6}$ In a case study, de Jong et $\mathrm{al}^{7}$ argued that the benefit of the use of cabergoline, another potent antagonist of the dopamine receptor like bromocriptine, has a long half-life, 14 to 21 days; therefore, a single dose of cabergoline is often sufficient.

The patient reported by Melo et al ${ }^{1}$ was a 16 -year-old with a diagnostic of PPMC without history of coronary artery disease. She had a prolonged hospital stay in the intensive care unit (ICU) with severe ventricular arrhythmias and NYHA functional class III. A conventional treatment for heart failure was conducted for 30 days without improvement. So, due to the high morbidity and mortality of patients, the treatment with cabergoline was initiated with the consent of the patient and her family after explaining the side effects of drugs, including non-breastfeeding. In a recent national population-based study conducted in the US, the incidence and results of PPMC were investigated in details. The authors demonstrated an increased incidence rate of PPMC, from 8.5 per 10,000 live births in 2011 to 11.8 per 10,000 live births in 2014. It is important to note that the rate of maternal adverse events, defined as cardiac arrest, heart transplant, mechanical circulatory support, acute pulmonary edema, thromboembolism, or cardioverter/defibrillator implantable permanent pacemaker increased from $11.7 \%$ in 2004 to $15 \%$ in 2011. Similar trends were observed for in-hospital mortality, with an increase of $0.7 \%$ in 2004 to $1.3 \%$ in 2011 . These data show that despite the advances in medical care in Western societies over the past decade, the concepts of treatment so far failed to achieve improvements in the prognosis of patients with PPMC. Therefore, with the increasing incidence and prognosis of PPMC unchanged and the lack of treatment for specific diseases, there is an urgent need for new treatment strategies. ${ }^{6}$

The comment about the possibility of dopaminergic agonists as a therapy to be considered in these cases as an adjunct to standard treatment in developing countries was particularly important, because in these countries the availability of maternal intensive care units is precarious. There are no cessation of breastfeeding campaigns in these countries, and PPMC is already a growing problem. In this case, the patient had already suspended breastfeeding because of her medical conditions and her long stay in the ICU. In 2006, Fett and Murphy ${ }^{7}$ reported in Haiti a maternal mortality of $25 \%$ in patients with (PPMC) and the devastating effect of it on their children. It is precisely to avoid these unfortunate consequences that therapy should be considered. Maternal mortality should be reduced or eliminated in these cases, avoiding the effects of maternal loss in early childhood development.

Maria Adélia Medeiros e Melo Jordão Sousa Carvalho

Francisco Edson de Lucena Feitosa Edward Araujo Júnior Alberto Borges Peixoto

Francisco Herlânio Costa Carvalho Regina Coeli Marques Carvalho

\section{References}

1 Hilfiker-Kleiner D, Kaminski K, Podewski E, et al. A cathepsin D-cleaved $16 \mathrm{kDa}$ form of prolactin mediates postpartum cardiomyopathy. Cell 2007;128(3):589-600

2 Sliwa K, Blauwet L, Tibazarwa K, et al. Evaluation of bromocriptine in the treatment of acute severe peripartum cardiomyopathy: a proof-of-concept pilot study. Circulation 2010;121(13): 1465-1473

3 Hilfiker-Kleiner D, Meyer GP, Schieffer E, et al. Recovery from postpartum cardiomyopathy in 2 patients by blocking prolactin release with bromocriptine. J Am Coll Cardiol 2007;50(24): 2354-2355

4 Carlin AJ, Alfirevic Z, Gyte GM. Interventions for treating peripartum cardiomyopathy to improve outcomes for women and babies. Cochrane Database Syst Rev 2010;(9):CD008589

5 Elkayam U, Goland S. Bromocriptine for the treatment of peripartum cardiomyopathy. Circulation 2010;121(13):1463-1464

6 Haghikia A, Podewski E, Berliner D, et al. Rationale and design of a randomized, controlled multicentre clinical trial to evaluate the effect of bromocriptine on left ventricular function in women with peripartum cardiomyopathy. Clin Res Cardiol 2015;104(11): 911-917

7 Johnson-Coyle L, Jensen L, Sobey A; American College of Cardiology Foundation; American Heart Association. Peripartum cardiomyopathy: review and practice guidelines. Am J Crit Care 2012; 21(2):89-98

8 Fett JD, Murphy JG. Infant survival in Haiti after maternal death from peripartum cardiomyopathy. Int J Gynaecol Obstet 2006; 94(2):135-136 